ejd150659

\title{
Omalizumab: what benefits should we expect?
}

Ana GIMÉNEZ-ARNAU ${ }^{1}$

Manel VELASCO ${ }^{2}$

Jose Carlos ARMARIO HITA ${ }^{3}$

Moises LABRADOR-HORRILLO ${ }^{4}$

Juan Francisco SILVESTRE SALVADOR ${ }^{5}$

${ }^{1}$ Dermatology Department, Hospital del Mar, Barcelona,

${ }^{2}$ Dermatology Department, Hospital Arnau de Vilanova, Valencia,

${ }^{3}$ Department of Surgical and Clinical Dermatology and Venerology, Hospital Universitario de Puerto Real, Cádiz,

${ }^{4}$ Allergy Section, Internal Medicine Department, Hospital Vall d'Hebron, Barcelona, ${ }^{5}$ Dermatology Department, Hospital General Universitario de Alicante, Alicante, Spain

Short title: The benefits of omalizumab in chronic spontaneous urticaria

\section{Reprints:}

Ana Giménez-Arnau

<anamariagimenezarnau@gmail.com>

Article accepted on $14^{\text {th }}$ March, 2016 


\begin{abstract}
Background. Chronic spontaneous urticaria (CSU) is a skin disease characterised by wheal appearance, swelling, itching, and painful skin. Omalizumab has been used for CSU treatment demonstrating good efficacy. Objectives. To investigate the efficacy and safety of omalizumab treatment in CSU patients in real-life practice. Materials \& methods. A retrospective analysis was performed on 38 patients suffering from CSU who received $300 \mathrm{mg}$ of omalizumab every four weeks. Results. After omalizumab treatment, $68.4 \%$ of patients showed a complete response (UAS7=0). All the patients were able to stop treatment with corticosteroids, cyclosporine, and anti-leukotrienes, and only $39.5 \%$ of patients remained on anti-histamines. Omalizumab treatment led to a $96 \%$ and $65 \%$ decrease in emergency room and primary health care visits, respectively, as well as a reduction in the direct costs associated with the disease. No omalizumabrelated adverse events were reported. Conclusion. Omalizumab exhibits good efficacy in alleviating the symptoms of CSU, leads to a decrease in concomitant medication use, restores patients' quality of life, and has economic benefits by reducing disease-related health care costs.
\end{abstract}

Key words: omalizumab, chronic urticaria, efficacy, health care, safety 
Chronic spontaneous urticaria (CSU) is a serious and troubling skin disease $[1,2]$. The global prevalence of chronic urticaria is $1 \%$ of the world population and up to two thirds of these patients suffer from CSU [3, 4]. It is twice as common in women than men [4]. CSU symptoms include oedematous-type skin reactions, pruritus $[1,2,4]$, and, in $40 \%$ to $50 \%$ of people suffering from CSU, angioedema [5]. Symptoms appear spontaneously without any specific external cause $[4,6]$. Research on the underlying aetiology of CSU has highlighted the role of autoimmunity. Moreover, some foods or infections have been implicated, and other factors such as stress, fatigue, and drugs are well recognized as aggravating factors [2].

CSU can significantly affect the quality of life (QoL) [6] of patients, leading to negative effects, such as insomnia and psychological comorbidities (e.g. depression or anxiety) [4]. Patients also experience difficulties at work and more than half loose at least one day of work per month due to urticaria [6]. Up to now, CSU treatment includes licensed doses of non-sedating antihistamines, with increasing off-label dosing up to four-fold as a second-line step. Third-line treatment includes systemic corticosteroids (only short courses for acute exacerbations), cyclosporine [5, 7, 8], omalizumab [8], or antileukotrienes [8]. Omalizumab has been used for treatment of chronic urticaria demonstrating good efficacy in alleviating the symptoms of the disease [9-13]. In February 2014, its use was approved for CSU in Europe.

In the present study, we collected data on the efficacy and safety of omalizumab treatment in $38 \mathrm{CSU}$ patients from five hospitals representing real-life practice. The benefits of omalizumab over current available treatments for CSU are discussed.

\section{Methods}


A retrospective descriptive analysis was carried out for 38 patients, from five hospitals, suffering from active CSU which was refractory to: high doses of $\mathrm{H} 1$ antihistamines $(n=38)$, third-line treatment according to the EACCI guidelines (cyclosporine: $n=3$; montelukast: $n=3$; corticosteroids: $n=2$ ), and other therapeutic options (doxepine: $n=5$; dapsone, $n=1$ ) [8]. The mean weekly Urticaria Activity Score (UAS7), in spite of the treatment, showed severe urticaria activity (mean UAS7=29.1 \pm SD [standard deviation] 7.68). Omalizumab was prescribed at the time as an off-label treatment.

Patients were treated from January 2010 to January 2015. CSU was defined based on the symptoms mentioned above. As shown in table 1 , the extended exploratory study commonly performed included analysis of: blood count, erythrocyte sedimentation rate, biochemistry, total IgE, and complete thyroid function (TSH, T3, T4, anti-TPO, and anti-thyroglobulin), as well as allergy skin tests to rule out type I allergy, the Autologous Serum Skin Test (ASST), and the Autologous Plasma Skin Test (APST). Occasionally, a lesional skin biopsy, an investigation for infection, or an assessment of autoantibodies (e.g. antinuclear) was performed.

All patients were treated with $300 \mathrm{mg}$ omalizumab subcutaneously every four weeks. Omalizumab was used for all patients as an off-label treatment, as approved by the Spanish Agency for Drugs and Health Products, as well as each respective hospital committee, which included written consent.

The main outcomes documented in order to analyse response to omalizumab treatment (improvement of symptoms) were:

(1) UAS7, which can vary from 0 to 42 per week.

(2) The Chronic Urticaria Quality of Life Questionnaire (CU-Q2oL); a scale of life quality with 23 items grouped into six categories associated with the disease: itching (two questions), swelling (two questions), activities (six questions), sleep (five 
questions), limitations (three questions), and appearance (five questions). Each item of the CU-Q2oL score ranges from 0 to 4; a high score is indicative of a poor QoL [14].

(3) Frequency of adverse and serious adverse events (safety events), and the relationship of these with the study drug. We defined a complete response as a UAS7 score equal to $0[7,15]$, a significant response as a UAS7 score of $>0$ and $<6$, and a partial response as reduction in symptoms by more than $30 \%$ but a UAS7 score $>6$. We defined exacerbations as flares of urticaria in which red and/or itchy hives appeared on the skin. Patients were examined for the above prior to omalizumab treatment and during the last visit in which omalizumab was administered.

In order to assess additional benefits of omalizumab over current available treatments for CSU, an evaluation of impairment of patient QoL and health resources consumed was conducted.

The categorical variables were described as absolute and relative frequencies, whereas the continuous variables were reported as the mean $( \pm \mathrm{SD})$ and /or median (plus range). Descriptive statistics were performed using SAS software version 9.4 for Windows (SAS Institute Inc., Cary, NC, USA). Values of $p>0.05$ were considered to indicate statistical significance.

\section{Results}

Baseline demographic and clinical characteristics of the sample (38 patients) are summarised in Table 1. For the overall population, the mean $( \pm \mathrm{SD})$ age was $48.1 \pm 13.96$ years; women comprised $65.8 \%$ of the patients. The median period of time $(\mathrm{Q} 1, \mathrm{Q} 3$; interquartile range) from diagnosis was $4.0(1.2,8.0)$ years, and the median time from onset of symptoms was $5.0(3.0,9.0)$ years. The main diagnostic tests performed for 
CSU diagnosis were: blood tests (33 patients; 86.8\%), allergy skin tests (12 patients; $31.6 \%$ ), and the autologous serum skin test (ASST)/autologous plasma skin test (APST) (nine patients; $23.7 \%$ ), as well as analysis of $\operatorname{IgE}$ (nine patients; $23.7 \%$ ) and TSH (seven patients; 18.4\%). The median period of time (Q1, Q3) from onset of omalizumab treatment was $6.5(2.0,24.0)$ months (Table 1).

1 Prior to the start of omalizumab treatment, the entire population (100.0\%) was on 2 antihistamines $(68.4 \%$ on non-sedative antihistamines, $31.6 \%$ on sedative 3 antihistamines, and $18.4 \%$ on non-specified antihistamines), $78.9 \%$ were on 4 corticosteroids, $39.5 \%$ were on cyclosporine, and $26.3 \%$ were on antileukotrienes (

10 Table 2). Once treatment with omalizumab was started, only $39.5 \%$ of patients were on antihistamines and none of them were treated with either corticosteroids, cyclosporine, or anti-leukotrienes ( 
Table 2).

18 There was a significant improvement in the UAS7 after treatment with omalizumab. 19 The median (Q1, Q3) UAS7 was $28.0(22.0,35.0)$ and $0.0(0.0,2.0)$ before and after 20 omalizumab therapy, respectively (

26 Table 2). Before omalizumab treatment, $92.1 \%$ of the patients (all the subjects who 27 were evaluated for UAS7 pre-treatment) showed a UAS7 score greater than 6 , whereas 28 after treatment with the drug, $68.4 \%$ had a UAS7 score of 0 and $23.7 \%$ a UAS score 29 lower than 6 but higher than 0 . Only three patients (7.9\%) remained with a UAS7 score above 6 but lower than 13 ( 
Table 2). Moreover, during the treatment with omalizumab, there was a decrease in the number of patients suffering from exacerbations (from $89.5 \%$ to 13.2\%) and angioedema (from $39.5 \%$ to $5.3 \%$ ). The duration of omalizumab treatment was variable, ranging from two months (two patients) to 27 months (one patient), and all the patients had ongoing treatment when data were collected for analysis.

The only adverse effect reported by a patient consisted of non-specific discomfort and was not attributed to drug administration.

36 Finally, the use of resources (emergency room [ER] and primary health care visits) and 37 time off work due to sick leave decreased after omalizumab treatment ( 
Table 2). The number of patients visiting the ER was $27(71.1 \%)$ and $1(2.6 \%)$ before and after omalizumab treatment, respectively. Twenty-three $(60.5 \%)$ patients visited primary health care centres before treatment with omalizumab versus $8(21.1 \%)$ patients after omalizumab treatment (table 2). Accordingly, both the median (Q1, Q3) direct costs of ER visits decreased from $372.6(0.0,750.4)$ to $0.0(0.0,0.0)$ euros and the median direct costs of primary health care visits decreased from $225.6(0.0,360.0)$ to $0.0(0.0,6.4)$ euros (table 2$)$. The CU-Q2oL test was performed on nine patients. The QoL test showed a statistically significant increase in QoL after treatment with omalizumab (mean [SD] of 72.7 [18.89] pre-omalizumab versus 12.8 [10.34] postomalizumab treatment) (table 2).

\section{Discussion}

The standard treatment for chronic spontaneous urticaria, as recommended by guidelines, is non-sedating anti-H1 antihistamines as first-line therapy, with an increase in off-label dose up to fourfold as a second-step, and systemic corticoids for acute exacerbations and cyclosporine, omalizumab, and anti-leukotrienes as third-line treatment $[5,7,8]$. In addition to guidelines [8] that recommend omalizumab for CSU 
treatment, there are several studies that have shown omalizumab therapy to be an effective treatment option for patients with CSU [12, 16-18].

We present descriptive retrospective data from patients suffering CSU who were treated with omalizumab. A limitation of this study is the retrospective design, in which omalizumab was administered at a dose of $300 \mathrm{mg}$ every four weeks, as off-label treatment in a real-life practice. Another limitation of the present study is the small sample size $(n=38)$, although it is noteworthy that even with the small size, the results are statistically significant. Moreover, the results are consistent with previous published results of 110 omalizumab-treated patients [19].

43 Omalizumab administered at $300 \mathrm{mg}$ every four weeks alleviated CSU symptoms (the 44 number of angioedemas) and allowed concomitant medication use to be lowered. After treatment with omalizumab, a higher rate of angioedema-free patients was observed (

51 Table 2). In addition, after omalizumab treatment, only 15 patients were treated with 52 concomitant medications (anti-histamines) versus all patients $(n=38)$ treated with anti53 histamines before treatment; the majority of the latter were receiving other therapies (e.g. corticosteroids, cyclosporine, or anti-leukotrienes) before treatment with 
omalizumab. In support of the improvement in CSU, we found that omalizumab treatment significantly reduced the UAS7 score. Of all the 38 patients, 35 subjects had a pre-omalizumab UAS7 score which was greater than 6 in 100\% of the subjects, whereas after treatment $92.1 \%$ of the patients had a UAS7 score $\leq 6$ (26 patients [68.4\%] presented a complete response [UAS7=0]) (

Table 2). Only three patients showed a partial response with a UAS7 score of $>6$ [8-12] due to a slower response and the concomitant involvement of known exacerbating factors, e.g. NSAIDs. Along the same lines, previous studies have shown an improvement in the UAS7 score. The majority of patients $(52 \%[20,21]$, and $66 \%$ [11]) after treatment with $300 \mathrm{mg}$ of omalizumab showed a UAS7 score of $<6$.

Previous studies have shown a significant association between omalizumab treatment and a reduction in the number of exacerbations, ER visits, corticoid use, and an improvement in patients' QoL $[22,23]$. Our findings are in line with these previous studies. The number of patients visiting the ER and primary health care centres clearly decreased after treatment with omalizumab, as well as all the direct costs involved (table 2). Moreover, all concomitant medication decreased and QoL improved (table 2). 
Regarding the QoL, although this was only evaluated in nine patients in the sample, the CU-Q2oL test performed to assess the QoL showed a statistically significant improvement after treatment with omalizumab. The results of these nine patients demonstrate the importance of these tests to reflect the improvement in QoL, as well as improvement with regards to the symptoms (e.g. UAS7) of the disease.

Regarding omalizumab safety, only one patient suffered an adverse event but this was considered not to be related to the drug. Overall, the safety profile of the present study matches with previously reported good safety profiles [10, 11, 20, 21]. All studies showed a similar incidence of adverse events between both groups (omalizumab vs placebo), with no trends or clinical difference resulting from or associated with omalizumab.

In conclusion, we present data of 38 patients suffering from CSU who received $300 \mathrm{mg}$ of omalizumab every four weeks. In this study, $68.4 \%$ of patients showed a complete response (UAS7=0) after omalizumab treatment and all the patients were able to stop corticosteroids, cyclosporine, and anti-leukotrienes. Thus, omalizumab demonstrated significant effectiveness and a safe profile which markedly alleviated disease symptoms, decreasing concomitant medications and restoring patient QoL. Finally, omalizumab offers benefits in reducing the economic impact and costs of disease treatment by decreasing ER and primary health care visits, as well as time taken off work due to sick leave. All the results presented in this study support and confirm the recommendation made by the EAACI and WAO guidelines $[5,7,8]$ in which omalizumab is included for the treatment of CSU as third-line therapy. Nevertheless, further research is required in order to compare between omalizumab and other treatments for CSU, to determine its place in CSU therapy. 


\section{Acknowledgements}

The authors would like to thank Anaïs Estrada (TFS Develop) for her assistance in manuscript preparation.

\section{Conflict of interests}

JF Silvestre, M Labrador-Horrillo and M Velasco received speakers' honoraria and/or consultant fees from Novartis. A Giménez-Arnau is a medical advisor for Uriach Pharma, Genentech, Novartis Pharma, Almirall; received Research Grants supported by Intendis-Bayer, Uriach Pharma, and Novartis Pharma; and participated in educational activities sponsored by Uriach Pharma, Novartis, Genentech, Menarini, GSK, MSD, Almirall, Leo Pharma. The other authors have no conflict of interest to declare.

\section{Funding}

This study was not financially supported. 


\section{References}

1. American Academy of Allergy Asthma and Immunology (AAAAI) website. Skin Allergy Overview, 2014. Available at: available at: http://www.aaaai.org/conditionsand-treatments/allergies/skin-allergies.aspx

2. Asthma and Allergy Foundation of America (AAFA) website. Chronic Urticaria (Hives), 2014. Available at: http://www.aafa.org/display.cmf?id=9\&sub=23\&cont=328

3. Kulthanan K, Jiamton S, Thumpimukvatana N, Pinkaew S. Chronic idiopathic urticaria: prevalence and clinical course. J Dermatol 2007; 34(5): 294-301.

4. Maurer M, Weller $\mathrm{K}$, Bindslev-Jensen $\mathrm{C}$, et al. Unmet clinical needs in chronic spontaneous urticaria. A GA2LEN task force report. Allergy 2011; 66(3): 317-30.

5. Sánchez-Borges M, Asero R, Ansotegui IJ, et al. Diagnosis and treatment of urticaria and angioedema: a worldwide perspective. World Allergy Organ J 2012; 5(11): 125-47.

6. O'Donnell BF, Lawlor F, Simpson J, Morgan M, Greaves MW. The impact of chronic urticaria on the quality of life. Br J Dermatol 1997; 136(2): 197-201.

7. Zuberbier $\mathrm{T}$, Asero R, Bindslev-Jensen $\mathrm{C}$, et al. EAACI/GA ${ }^{2} \mathrm{LEN} / \mathrm{EDF} / \mathrm{WAO}$ guideline: management of urticaria. Allergy 2009; 64(10): 1427-43.

8. Zuberbier $\mathrm{T}$, Aberer $\mathrm{W}$, Asero $\mathrm{R}$, et al. The EAACI/GA(2) LEN/EDF/WAO Guideline for the definition, classification, diagnosis, and management of urticaria: the 2013 revision and update. Allergy 2014; 69(7): 868-87.

9. Büyüköztürk S, Gelincik A, Demirtürk M, Kocaturk E, Colakoğlu B, Dal M. Omalizumab markedly improves urticaria activity scores and quality of life scores in chronic spontaneous urticaria patients: a real life survey. J Dermatol 2012; 39(5): 43942 .

10. Maurer $\mathrm{M}$, Altrichter S, Bieber $\mathrm{T}$, et al. Efficacy and safety of omalizumab in patients with chronic urticaria who exhibit IgE against thyroperoxidase. J Allergy Clin Immunol 2011; 128(1): 202-9. e5.

11. Maurer M, Rosén $\mathrm{K}$, Hsieh $\mathrm{H}-\mathrm{J}$, et al. Omalizumab for the treatment of chronic idiopathic or spontaneous urticaria. N Engl J Med 2013; 368(10): 924-35.

12. Saini S, Rosen KE, Hsieh H-J, et al. A randomized, placebo-controlled, doseranging study of single-dose omalizumab in patients with $\mathrm{H} 1$-antihistamine-refractory chronic idiopathic urticaria. J Allergy Clin Immunol 2011; 128(3): 567-3. e1.

13. Song CH, Stern S, Giruparajah M, Berlin N, Sussman GL. Long-term efficacy of fixed-dose omalizumab for patients with severe chronic spontaneous urticaria. Ann Allergy Asthma Immunol 2013; 110(2): 113-7. 
14. Baiardini I, Pasquali $\mathrm{M}$, Braido $\mathrm{F}$, et al. A new tool to evaluate the impact of chronic urticaria on quality of life: chronic urticaria quality of life questionnaire (CUQoL). Allergy 2005; 60(8): 1073-8.

15. Młynek A, Zalewska-Janowska A, Martus P, Staubach P, Zuberbier T, Maurer M. How to assess disease activity in patients with chronic urticaria? Allergy 2008; 63(6): 777-80.

16. Carrillo DC, Borges MS, García E, Egea E, Serrano CD. Omalizumab vs. placebo in the management of chronic idiopathic urticaria: a systematic review. World Allergy Organ J 2014; 7(1): 72.

17. Groffik A, Mitzel-Kaoukhov H, Magerl M, Maurer M, Staubach P. Omalizumab-an effective and safe treatment of therapy-resistant chronic spontaneous urticaria. Allergy 2011; 66(2): 303-5.

18. Sánchez-Machín I, Iglesias-Souto J, Franco A, Barrios Y, Gonzalez R, Matheu V. T cell activity in successful treatment of chronic urticaria with omalizumab. Clin Mol Allergy CMA 2011; 9: 11.

19. Labrador-Horrillo $\mathrm{M}$, Valero A, Velasco $\mathrm{M}$, et al. Efficacy of omalizumab in chronic spontaneous urticaria refractory to conventional therapy: analysis of 110 patients in real-life practice. Expert Opin Biol Ther 2013; 13(9): 1225-8.

20. Kaplan A, Ledford D, Ashby M, et al. Omalizumab in patients with symptomatic chronic idiopathic/spontaneous urticaria despite standard combination therapy. J Allergy Clin Immunol 2013; 132(1): 101-9.

21. Saini SS, Bindslev-Jensen C, Maurer M, et al. Efficacy and safety of omalizumab in patients with chronic idiopathic/spontaneous urticaria who remain symptomatic on $\mathrm{H} 1$ antihistamines: a randomized, placebo-controlled study. J Invest Dermatol 2015; 135(1): 67-75.

22. Levy AN, García A, Ruiz AJ, García-Agua Soler N, Sanjuan MVH. Costeffectiveness of omalizumab in severe persistent asthma in Spain: a real-life perspective. J Asthma 2015; 52(2): 205-10.

23. Lafeuille M-H, Dean J, Zhang J, Duh MS, Gorsh B, Lefebvre P. Impact of omalizumab on emergency-department visits, hospitalizations, and corticosteroid use among patients with uncontrolled asthma. Ann Allergy Asthma Immunol 2012; 109(1): 59-64. 
Table 1. Baseline characteristics of the patients.

\begin{tabular}{lc}
\hline \multicolumn{1}{c}{ Demographic } \\
\hline $\mathrm{N}$ (total) & 38 \\
Female (n, \%) & $25(65.8 \%)$ \\
Age (years) & $48.1(13.96)$ \\
$\quad$ Mean (SD) & \\
\hline Clinical & $6.6(8.08)$ \\
\hline Time since diagnosis & $4.0(1.2,8.0)$ \\
Mean, (SD), years & $1(2.6 \%)$ \\
Median (Q1, Q3), years & $2(5.3 \%)$ \\
$<3$ months, n $(\%)$ & $6(15.8 \%)$ \\
3 - <6 months, $\mathrm{n}(\%)$ & $29(76.3 \%)$ \\
6 - <12 months, n (\%) & \\
$\geq 1$ year, n (\%) & $7.9(7.73)$ \\
Time from onset of symptoms (years) & $5.0(3.0,9.0)$ \\
Mean (SD), years & \\
Median (Q1, Q3), years & $33(86.8 \%)$ \\
Main diagnostic tests ${ }^{\mathrm{a}}$ & $12(31.6 \%)$ \\
Blood count, biochemistry & $9(23.7 \%)$ \\
Allergy skin tests, type I allergy & $9(23.7 \%)$ \\
ASST/APST & $7(18.4 \%)$ \\
Total IgE & $5(13.2 \%)$ \\
Complete thyroid function & \\
Others &
\end{tabular}

${ }^{\mathrm{a}}$ The sum is over $100 \%$ because some patients underwent more than one diagnostic test. 
Table 2. Comparison of clinical response pre-omalizumab versus post-omalizumab treatment.

\begin{tabular}{|c|c|c|}
\hline & $\begin{array}{l}\text { Pre-omalizumab } \\
\text { No. patients }(\%)\end{array}$ & $\begin{array}{l}\text { Post-omalizumab } \\
\text { No. patients (\%) }\end{array}$ \\
\hline \multicolumn{3}{|l|}{$\mathrm{UAS7}^{\mathrm{a}}$} \\
\hline Mean (SD) & $29.1(7.68)$ & $1.4(2.90)$ \\
\hline Median (Q1, Q3) & $\begin{array}{c}28.0 \\
(22.0,35.0)\end{array}$ & $\begin{array}{c}0.0 \\
(0.0-12.0)\end{array}$ \\
\hline 0 & $0(0.0 \%)$ & $26(68.4 \%)$ \\
\hline$>0-<=6$ & $0(0.0 \%)$ & $2(5.3 \%)$ \\
\hline$>6$ & $35(92.1 \%)$ & $3(7.9 \%)$ \\
\hline Missing & $3(7.9 \%)$ & $7(18.4 \%)$ \\
\hline Exacerbations $^{\mathrm{b}}$ & $34(89.5 \%)$ & $5(13.2 \%)$ \\
\hline Angioedema $^{c}$ & $15(39.5 \%)$ & $2(5.3 \%)$ \\
\hline \multicolumn{3}{|l|}{ Use of resources } \\
\hline ER visits ${ }^{\mathrm{d}}$ & $27(71.1 \%)$ & $1(2.6 \%)$ \\
\hline Primary health care visits ${ }^{\mathrm{e}}$ & $23(60.5 \%)$ & $8(21.1 \%)$ \\
\hline Antihistaminic drugs & $38(100.0 \%)$ & $15(39.5 \%)$ \\
\hline Corticosteroids & $30(78.9 \%)$ & $0(0.0 \%)$ \\
\hline Cyclosporine & $15(39.5 \%)$ & $0(0.0 \%)$ \\
\hline Anti-leukotrienes & $10(26.3 \%)$ & $0(0.0 \%)$ \\
\hline Other $^{\mathrm{h}}$ & $10(26.3 \%)$ & $0(0.0 \%)$ \\
\hline \multicolumn{3}{|l|}{ Direct costs ${ }^{\mathrm{f}}$} \\
\hline ER visits, median (Q1, Q3) & $372.6(0.0,750.4)$ & $0.0(0.0,0.0)$ \\
\hline Primary health care visits, median $(\mathrm{Q} 1, \mathrm{Q} 3)$ & $225.6(0.0,360.0)$ & $0.0(0.0,6.4)$ \\
\hline \multicolumn{3}{|l|}{ Indirect costs } \\
\hline Sick leave $\mathrm{I}^{\mathrm{I}}$ & $8(21.1 \%)$ & $0(0.0 \%)$ \\
\hline \multicolumn{3}{|l|}{ Quality of life (DLQI test) $n=9^{\mathrm{g}}$} \\
\hline Mean $(\mathrm{SD})$ & $72.7(18.89)$ & $12.8(10.34)$ \\
\hline
\end{tabular}

${ }^{a}$ UAS7 data was not available for three patients and seven patients, pre-omalizumab and post-omalizumab, respectively; ${ }^{b} p<0.0001$ (pre- vs post-omalizumab); ${ }^{c} p=0.0002$ (prevs post-omalizumab), data from one patient was not available in the post-omalizumab group; ${ }^{\mathrm{d}} p<0.0001 ;{ }^{\mathrm{e}}$ data was unavailable for seven patients and 16 patients from the preand post-omalizumab group, respectively; $p=0.0005 ;{ }^{\mathrm{f}} p<0.0001 ;{ }^{\mathrm{g}} p=0.0039$ (pre- vs post-omalizumab); hapsona, doxepina, antibiotics, eradication of Helicobacter pylori, and hydroxyzine; 'the number of times the patient was told to stop work by the doctor. 